\title{
On the Strategies of Improving the Teachers' Teaching Abilities Based on Teaching State Diagnosis
}

\author{
Xuelian Lu \\ Tonghua Normal University, College of Education Science, Jilin Province, Tonghua City, 134002, \\ China. \\ luxuelian1982@sina.com
}

\begin{abstract}
Teachers' teaching ability is the key to determine teaching quality and teachers' teaching abilities weaken under the teaching state diagnosis. This phenomenon has been a bottleneck of the constraint on the quality of education and teaching .To analyze the teachers' weakened teaching abilities objectively and examine its causes rationally will be helpful to explore the solutions and developing thinking of improving teachers' teaching abilities to make the teachers' professional capacity confirmed, reconstructed and improved.
\end{abstract}

Keywords: Teaching State Diagnosis; teachers' teaching abilities; improving strategies; teachers' professional capacity.

\section{基于教学状态诊断的教师教学能力提升路径探析}

\author{
陆雪莲 \\ 通化师范学院教育科学学院, 吉林通化, 中国
}

摘 要: 教师教学能力是提高学校教学质量的关键, 教学状态诊断下教师教学能力存在弱化 现象。教师教学能力弱化已成为制约教育教学质量的 “瓶颈”, 客观分析教师教学能力弱化 现状, 理性剖析其诱因, 有助于探寻提升教师教学能力解决路径和发展思路, 真正使教师的 能力素质得以确认、重构和提高。

关键词: 教学状态诊断; 教师教学能力; 提升路径; 能力素质。

\section{1 . 前言}

教学状态是教师进行课堂教学时在心态、身体、教学方法等综合作用下所处的状态, 教 学状态好坏直接影响教师教学能力。教师教学能力是一种引导能力, 是引领学生从此岸走向 彼岸的能力。通过教师的引导, 学生可以把外在的知识和能力转化为内在的知识。

\section{2. 教学状态诊断下教师教学能力: 表现、弱化诱因、提升路径}

\section{1. 教学状态诊断下教师教学能力的主要表现}

2.1.1 教学主动性衰退与 “超越自我” 的能力素质要求有较大差距

一是消极被动, 忽视对教学目标进行科学分析, 缺乏应有的质疑精神和批判思维, 对教育教 学所需要的教学改革敷衍了事。二是看似积极跟进新的教育理论和教学方法, 实质上却人云 亦云，不能联系教学对象实际并富有成效地开展针对性教学。三是缺乏对课堂生成性问题的 预判能力, 不能积极主动设计各种预案。

2.1.2 教学能动性疲软与 “能动开发” 的能力素质要求有较大差距

教学缺乏能动性, 主要是存在惰性和盲目性。教育教学需要教师具备 “谋划学科建设、开发 新课程、开发利用教学资源”的能力。然而, 教师有三个方面能动性疲软表现。一是缺乏渗 
透思想的视野和方法, 学历教育中单纯进行知识传递的痕迹尚存。二是盲目、过度使用多媒 体, 重外在表现形式轻内在结果。三是误将启发式教学简单等同于提问题, 没有根据教学内 容需要和学生认知特点提出适宜问题。

2.1.3 教学创造性贫乏与 “不断创新” 的能力素质要求有较大差距

教育教学具有指向性、实用性和时效性较强的特点, 决定了其学科专业的多样化以及课程课 题、教学内容动态发展的生态方式。教育教学要求教师 “能够针对本学科专业领域的重大理 论问题, 带领团队集智攻关并取得创新成果”。然而, 教师发挥创造性现象鲜见, 教学效果 并不佳。此外, 教学方式单一, 研讨式、启发式、自主式、辩论式、答疑式、问题导入式、 情景模拟式、网络互动式等教学方法用得不多, 相当数量的教师把教学变成自己的“独角戏”, 远不能满足课堂教学中学生希望进行深入互动教学的需求。

2. 2. 教学状态诊断下教师教学能力弱化的主要诱因

2.2.1 教育教学过于繁琐的标准化教学管理, 某种程度上束缚了教师教改的积极性的发挥 在当前教育教学管理体制下, 各种细致入微的规章制度对教学的控制愈发形式化、程序化、 工艺化, 教师从课程内容的规划、教学方式的选择到教学程序的制定, 都要受到行政部门的 监督与约束。在日益严密规范的教学管理制度面前, 教师个人的热忱、兴奋以及伤感、失意 等, 有时会被自动隐忍, 教师自主精神和创造意识会淡化。

2.2.2 教育教学畸轻畸重的教师评价机制, 很大程度上导致教师能动性发展偏向

当前评价体制衡量教师工作, 往往只看完成了多少任务、发表了多少篇文章, 而很少看教师 的精力是否用在了钻研教学上、用在解决教育教学的实际问题上、用在服务和指导学生训练 上。在这种评价机制的引导下, 教师片面重视专业学术科研, 忽视教学反思和实践研究的现 象不可避免, 特别是相互攀比 “为获奖而搞成果” 有泛滥之势; 加上对专业技术教师的评价 存在 “看谁获得的成果奖级别高、等级高” 的现象, 诱发了“唯虚不唯实、唯上不唯下、唯 钱不唯真” 的学术不实现象。

2.2.3 经验消解了理性, 导致能动精神弱化

目前, 教师来源主要有两类: 一类是从社会或校外选调而来, 多数也是从学历教育转型而来 的, 通过教育实践的磨砺, 积累了相当丰富的教学经验, 形成了一些有效的做法; 另一类是 从院校毕业直接而来, 通过不断理论学习和进修提高, 积淀了一定的学科知识, 也形成了一 些教学经验和习惯做法。不管哪类教师在教师角色定位上, 必须走出过去经验, 转变为 “应 变实践式教师”, 因为能成为高层次优秀人才的大多数教师, 都是通过了优秀的课堂教学、 完成了重大的任务和承担了大量的工作，以及多年教学岗位任职等途径，去完成了 “取另一 类教师之长补上自身之短板” 的过程, 实现了 “两类教师的经历轨迹产生交叉共振效益”。 2.2.4 从众消解了个性, 导致个性失落

不落俗套、个性鲜明, 实际上就是教师发挥并升华了主体意识, 这样的教师无疑最受学生欢 迎。相反, 从众心理和行为是消解教师能动性的腐蚀剂。但是, 面对现实存在的 “教而优则 仕, 仕而优则不教” 的现象, 有的教师就容易失去自我, 价值取向在不知不觉中发生偏移, 把仕途的晋升看作教学的最高境界。

2.3. 提升教师教学能力的主要路径

2.3.1 完善 “教师任教资格考评制度”，理顺教师 “任教资格” 与 “上课资格”之间的关系 教师通过任教资格审定后取得的只是 “岗位准入资格”，并不是说就取得了一线登台教学的 “岗位胜任资格”。“学生的需求必须摆在教学的第一位” 这一理念体现在选派教师上, 要 求遴选基于专题教学的 “优质教师” 担任一线教学。即依据标准, 结合全体学生通过教学质 量评价系统对一线任课教师评价的情况, 以及院校督导组进行教学督导的情况, 在比较中遴 选出基于专题教学的 “优质教师” 来担任一线教学任务。教师只有充分发挥自身的主观能动 性, 在讲台下历练成长, 在取得 “岗位胜任资格” 并成为某一专题的 “优质教师”之后, 院 校才能安排其承担这一专题的一线教学任务。 
2. 3.2 着力改革教师的代（挂）职形式，动态夯实教师的专业基础

一方面, 既要通过拓宽教师代（挂）职的途径，加大教师到其他院校代（挂）职交流与管理 的力度, 又要认定并鼓励初、中级教师在所在院校内部进行代 (挂) 职; 另一方面, 要考虑 教师是否会因代 (挂) 职而影响教学科研工作或给家庭生活带来困难的实际情况, 从有利于 调动教师代 (挂) 职积极性的角度改革教师代（挂）职时间。

2.3.3 强化教师服务学生的意识和能力, 加快教师能力素质转型的步伐

教育教学的效益直接指向学生学习需要的满足, 这就需要教师能力要进行改革创新。针对有 些教师对学生实际情况、岗位需求、新信息新知识的了解和掌握可能慢于学生、少于学生、 落后于学生的现状, 在某些方面教师与学生之间还可能发生 “素质与能力逆转” 的现象, 因 此要通过服务学生来牵引教师能力素质转型, 通过承担和完成机关或学生的任务, 提升教师 胜任教育教学工作的能力素质。特别是要通过为学生授课、参与学生活动、为学生提供决策 咨询任务、运用研究成果为学生提供支持等方式, 细化量化和提高各类各级教师服务学生的 能力。

2.3.4 建立 “教育教学集体备课机制” ，集中团队智慧把交给学生的每一堂课都打造成精品 教育教学的教学内容, 既要求理论的深刻性, 又要求实践的应用性。既然 “两类教师的经历 轨迹产生交叉共振效益” 在同一人身上不易实现, 精品的教育教学课就可能成为多数教师难 以独立完成的任务, 我们就应该广泛采用集体备课的方式, 通过团队的力量来达成取长补短 之功效。

2.3.5 建立起由专任教师、内聘教师及外聘教师构成的教师教学队伍

结合院校实际, 在充分借鉴其他院校教学经验的基础上, 可以逐步建立起由专任教师、内聘 教师及外聘教师组成的教师队伍。一是以专任教师为主体。使用专任教师有利于院校与学生 同步一体发展, 对于培养岗位指向性明确的教育教学具有独特优势是冊庸置疑的。但要避免 院校处于教学新手偏多的状态, 从顶端保证教学的连续性。二是以内聘教师为增援。内聘教 师为院校内除专任教师以外的能为学生授课的优秀机关人员或教辅人员, 这样可以使院校教 师队伍结构多元化, 也能从校内开发更多的优秀教师资源。三是以外聘教师为重要补充。在 外聘教师的聘任中要始终坚持 “两个不动摇” : 坚持外聘教师只能作为教师队伍的一支补充 力量, 决不能动摇专任教师在队伍中的主导地位; 坚持外聘教师聘用的高标准原则, 决不能 动摇以外聘人员提升教师队伍学术水平的初衷和出发点。

\section{3. 结论}

通过 “教师任教资格考评制度的完善、教师代（挂）职形式的改革、教师服务学生意识与能 力的强化、集体备课机制的建立、教师教学队伍的有效建设” 等一系列策略, 提升教师教学 能力。

\section{4. 致谢}

基金项目:

1. 吉林省高等教育教学改革 2016 年度重点课题《高校教学质量监控体系的构建与运行研究》 阶段性成果

2. 通化师范学院高等教育教学改革重点课题《基于需求导向的创新型学前人才培养模式研 究》阶段性成果, 项目编号: JY2016025

3. 通化师范学院高等教育教学改革重点课题《高校教学质量监控体系的构建与运行研究》阶 段性成果，项目编号：JY2016002 


\section{References}

[1]. Shouren Wang, Linmiao Shi.Focusing on the Improving of Teachers' Teaching Abilities Pushing Ahead with the Construction of the Teacher Education Development Center[J]. China University Teaching 2016,4, P75-80.

[2]. Yuexin Cao, Bowei Zhang. Research on the cultivation of College Teachers' teaching ability[J]. Journal of Northeast Normal University(Philosophy and Social Sciences Edition). 2016,2,P208-213.

[3]. Jing He. Research on the optimization of teaching ability evaluation mechanism of University Teachers[J]. Heilongjiang Researches on Higher Education.2015,1, P95-98.

[4]. Yu Tao, Congmin Ren. Research on the path and strategy of Higher Vocational Teachers' teaching ability development. Higher education research[J].2015,11, P50-54. 